\title{
ON AGGLUTINATION AND COAGULATION.
}

BY SVANTE ARRHENIUS.

Received July 14, Igos.

There are two different opinions prevailing regarding the nature of agglutination. The one, held by the advocates of so-called colloidal theory, is that the suspended particles, here bacteria or erythrocytes clump together and subside under the influence of electrolytes and of certain other substances (agglutinins); the other, held by the chemical school, was proposed by Duclaux, who held that agglutination depends on the coagulation of some substances in the cells and especially in their boundary parts, whereby the cells are, so to speak, glued or jammed together, whereupon they subside.

In order to elucidate this question, I have undertaken some experiments on the agglutination of erythrocytes by means of salts. Erythrocytes from ox blood were suspended in. solutions of sodium chloride ( 0.9 per cent.) or cane sugar ( 7 per cent.). The emulsions contained, respectively, 4 , I and 0.25 per cent. of erythrocy tes. To $5 \mathrm{cc}$. of such emulsions in test tubes were added different quantities of the salts investigated, expressed in I cc. of a molectlar ${ }^{2}$ solution as unit. The minimum quantity necessary for agglutination was noted and is given in the table below. If no agglutination takes place, the erythrocytes fall to the bottom of the test tube and show a certain degree of fluidity when the tube is inclined. This fluidity disappears if the erythrocytes are agglutinated.

The examination of the coagulation, or rather precipitation, was carried out so that erythrocytes were laked by means of water and the resulting fluid was diluted with the said solutions of sodium chloride or of cane sugar. The resulting solutions contained, respectively, I and 0.17 per cent. of the laked erythrocytes. If a salt solution is added to a quantity of this blood solution, a precipitate appears at a certain concentration. If still more salt is added the precipitate may disappear. This occurs with salts of tri- or tetravalent anions, with uranyl and lead salts. The minimum quantity of salt which is necessary to give an observable precipitate was sought.

All these determinations were carried out so that different quantities of the salt solutions were added to a series of test tubes, containing $5 \mathrm{cc}$. of the emulsion of erythrocytes or $5 \mathrm{cc}$. of the blood solution. Immediately after the addition of the salt solution the tubes were shaken and held at $37^{\circ}$ for 3 hours, whereafter they were left at room temperature during the night and the sediment examined the following day. The results are given in the table below.

1 Read at the New Haven Meeting of the American Chemical Society.

${ }^{2}$ For sulphuric acid the concentrations are given in equivalents, because the positive ion $\mathrm{H}$, which exerts the agglutinating power, can not be dissolved separately. 


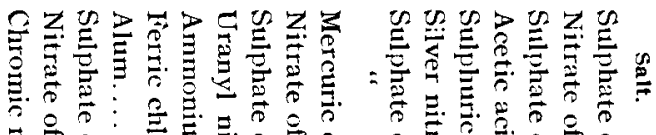

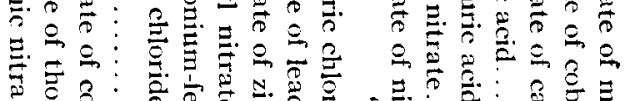

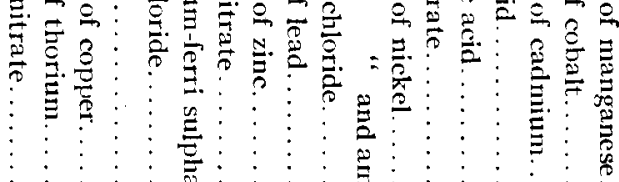

$+N \omega n$ w

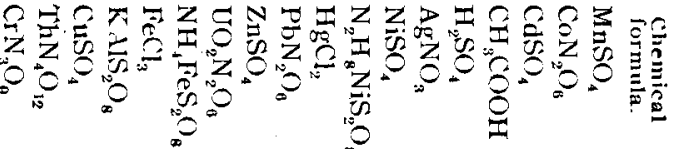
the cation.

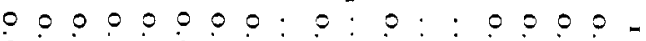

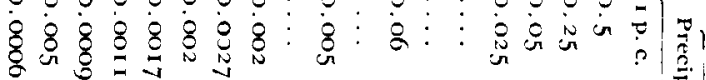
$0000.00000,0: 00000 \%$

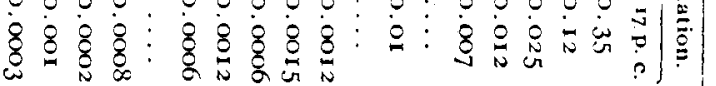

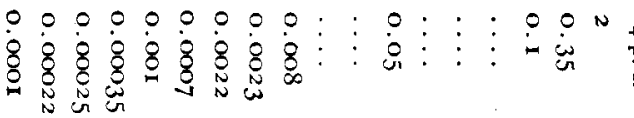

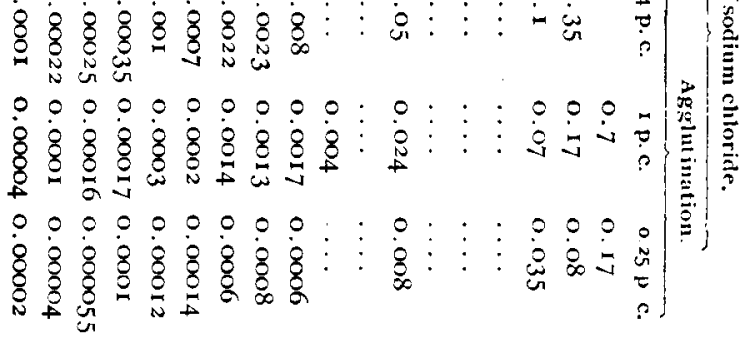

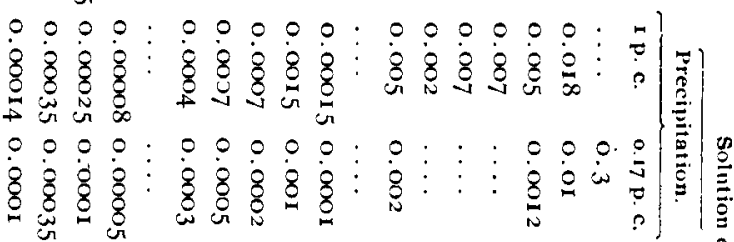

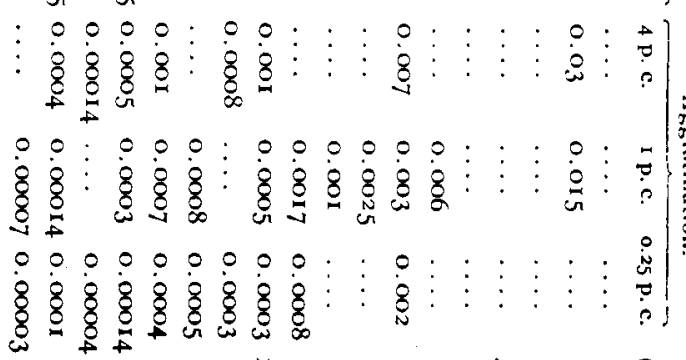

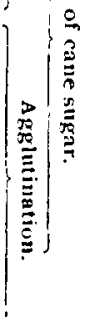

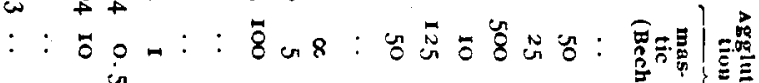

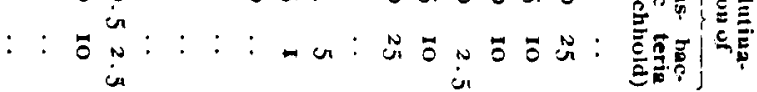


It will be seen from the table, which is arranged according to the agglutinating power in salt solution of the difierent salts, that there is a remarkable parallelism between this quantity and the precipitating power, nitrate of thorium in salt solution and uranyl nitrate in sugar solution being the only real exceptions.' It would also not be quite justifiable to demand an absolute proportionality between precipitating and agglutinating power. If all the precipitates had the same sticking power, then proportionality would naturally be expected, but the precipitates are of very difierent kind, according to their anion. The agreement between the two series is therefore as good as we might expect. There is, on the other hand, very little accordance between these series and the two series taken from Bechhold," which give an idea of the agglutinating power of different salts in regard to little drops of mastic or to bacteria. In the mastic series the influence of the electrolytic dissociation is very prominent, the weak electrolytes, acetic acid and mercuric chloride being very feeble agglutinants. Of this peculiarity we see no trace in my experiments on erythrocytes or on blood solution. In the bacteria series the sulphates of cadmium and of copper are of the same strength, whereas in my series they occupy places very near the ends of the table. There can therefore be no question that the agreement between the series of precipitation of laked blood and of agglutination of erythrocytes is more nearly perfect than that between these series and those given by Bechhold.

How close the agreement is between precipitation and agglutination is perhaps most clearly seen from the fact that salts giving a maximum of precipitation at a certain concentration, also, as we have found, give a maximal agglutination at a certain concentration. Where in one series the maximum does not appear it also fails in the other series. Now it is perfectly clear from many circumstances that the precipitation is a chemical process, as is even conceded by the most prominent advocates of the colloidal school for analogous cases, e. $g$., the precipitation of globulines by different salts. The different precipitates are widely different in color, flocculation and volume, $i . r$, the precipitating metal-ion exerts a great influence on the properties of the precipitate, which can hardly be understood if we do not suppose that the ion enters into it.

We may therefore conclude, with Duclaux, that agglutination depends upon a precipitation and that the precipitation in this case is due to a chemical reaction between the metal ions and the albuminous substances

1 The hemolytic action of silver nitrate and mercuric chloride prevents the rbservation of the minimum quantity causing agglutination. The figures in the table for these stbstances are therefore in reality too high, as is also seen on comparison with the figures regarding precipitation.

2Z. phys. Chem., 48, $3^{8} 5-423$ 
in the erythrocytes. It may be added that the salts of alkali and alkaline earth metals give no precipitation with laked blood nor in moderate concentrations do they agglutinate erythrocytes.

It is very apparent that the precipitation occurs with smaller concentrations of active salt in sodium chloride solutions than in sugar solutions. There is a possible explanation of this peculiarity. Lecithin ( $\mathrm{I}$ cc. of o. I per cent. emulsion to $5 \mathrm{cc}$. of I per cent. laked blood) gives a very voluminous precipitate with laked blood ( $\mathrm{I} \mathrm{cc}$.), but if the solution contains about I per cent. of sodium chloride the precipitate does not appear for two or three days, and is not so voluminous by far as without the sodium chloride. On the other hand, the solution is the more turbid in the sodium chloride tube if we except the first I 2 hours when the inverse is true. The same experiment may be made with the precipitate from laked blood ( 1 per cent.) on addition of 2 per cent. of O.I normal sulfhuric acid. After some time the fluid gets brownish and thereafter turbid, and a dark brown deposit subsides slowly on the bottom of the test tube. If I per cent. of sodium chloride is present these phenomena take place much more slowly, the precipitate does not appear for two or three days or longer, and the fluid remains dark brown for a yet longer time. The fluid clears up slowly near its surface, whereby it is quite apparent that the dark brown color is due to fine subsiding particles.

The experiment is still more striking if it is carried out with a mixture of sulphuric acid and lecithin, for then the precipitate is dark and voluminous. A great number of experiments in this direction showed that the presence of $\mathrm{I}$ per cent. of sodium chloride holds back the agglutination of the precipitated particles and hinders their sedimentation. This is in decided conflict with the ideas of the colloidal school, according to which all electrolytes promote agglutination and sedimentation. From the figures of the table we might be inclined to conclude that all the precipitates from laked blood are hampered in their sedimentation by the presence of sodium chloride (and probably of other alkali salts).

In most cases also the agglutination in sugar solution requires less quantities of salt than in salt solution. The salts of tri- and tetravalent ions are exceptions. A further investigation may perhaps elucidate the cause of this difierence.

Addition of lecithin holds back the agglutination in salt solution. In solution of cane sugar, where it gives a precipitate with the contents of the erythrocytes, it diminishes the velocity of sedimentation but increases the agglutination, which may easily be understood.

Many substances cause agglutination as well as hemolysis of the erythrocytes. Among the substances cited above, the acids, mercuric chlotide, and, as I have found, the nitrates of silver and of lead belong to this 
class. Regarding the acids I have already published an investigat:on. Here I have especially considered the mercuric chloride and the silver nitrate. If we acld increasing quantities of such a salt to a number of lest tubes, each containing $5 \mathrm{cc}$. of a 1 per cent. emulsion of erythrocytes. we at first find no sensible action, then an increasing degree of hemolysis. till this becomes complete, thereafter a long interval in which the complete hemolysis is reached more and more rapidly; finally the hemolysis decreases again and a deposit of aggiutinated erythrocytes appears, until at the end no sensible hemolysis but a rery rapid agglutinaticn occurs.

Some of these substances act very rapidly, as does silver nitrate, when the final results will be reached in an hour or so. In other cases the action is very slow, as with mercury salts, and then the limits at which complete hemolysis occurs are widlened, so that the interval increases with time-I have found two days necessary to reach the final limit. (With more diluted solutions the end values are reached in shorter time than with more concentrated ones.) The limiting values for mercuric chloride are 0.01 and 0.00015 for a 4 per cent. emulsion, and about 6 times less, namely, 0.0017 and 0.000027 for a 0.7 per cent. emulsion or as 70 to I in each case.

This is valid for salt solutions. For sugar solutions and I per cent. emulsion I have found the limits much nearer to each other, viz., 0.0009 and 0.0003 , or as 3 to $\mathrm{r}$. In such cases with slow action the erythrocytes are wholly subsided after 12 hours, and then the hemolysis goes on near the bottom of the test tube from which the color of hemoglobin diffuces slowly upwaris and forms a strongly colored meniscus, convex upwards, in German called "Kuppe" (hillock), which increases with time. If we now suppose that the interval of total hemolysis steadily diminishes, we will at the end find only one point of total hemolysis, and there after only the formation of a meniscus will be observed. This is the case with copper and uranyl salts in a high degree, but also with salts of aluminum, thorium, trivalent iron and cadmium. As will be seen from these data the hemolytic action does not run parallel with the agglutinating action.

For silver nitrate in sugar solution (I per cent. emulsion) the limits are 0.005 and 0.0008 or as 6 to 1 . Lead nitrate seems to behave nearlyin the same manner as the silver salt.

Sometimes, and especially for ferric and thorium salts, the high hydrolytic decomposition gives in greater concentrations a hemolytic action due to the free acid present.

As the hemolytic action interferes with the agglutinating one, the order of the agglutinating power of mercuric and silver salts is not adequately 
expressed by the minimum value of agglutinating salt, as is also evident from the table above.

Lecithin increases the velocity of hemolysis for silver as well as for mercuric salts. An addition of alcohol (2 per cent.) makes this increase still more pronounced. The final limits are not altered by these means.

It is not difficult to separate the supernatant fluid from the precipitate, caused by mercuric or silver salts, and to determine its content of mercuric or silver ions by means of its hemolytic action. In this manner I found that about 50 per cent. of the mercuric ions remained in $5 \mathrm{cc}$. of the salt solution with I per cent. emulsion to which I cc. of o.or normal mercuric chloride had been added. In $5 \mathrm{cc}$. of a sugar solution with $0.3 \mathrm{cc}$. of the same solution only 5 per cent. of the mercury ions were recovered. In the precipitate from $5 \mathrm{cc}$. of I per cent. emulsion of erythrocytes added with $0.1 \mathrm{cc}$. of 0.1 normal silver nitrate, 90 per cent. of the silver ions were retained. (All experiments at about $16^{\circ}$.)

These figures indicate that an equilibrium takes place between the precipitate and the active ions in the solution. That this is the case for other agglutinated masses also seems to be evident from the fact that the necessary quantity for agglutination is not independent of the quantity of erythrocytes nor porportional to this quantity. If no active ions were taken up in the precipitate, then the same concentration of salt would agglutinate as many erythrocytes as one might add to the solution. The value found would then be independent of the quantity of erythrocytes. This is not the case, but the necessary concentration increases with this quantity. Therefore we conclude that the active ions are bound in rather large number to the agglutinated erythrocytes. This is already evident from the conclusion that the agglutination depends on the formation of a precipitate containing the ions.

If now there were no equilibrium all the present active ions being bound to the agglutinated erythrocytes, then the necessary quantity of agglutinating salt would be strictly proportional to the quantity of erythrocytes. As this does not occur, an equilibrium must take place between the active ions in the fluid and those consumed by the agglutinating process, just as we have found to be the case for mercuric and silver salts.

There is still a peculiarity which needs to be scrutinized further. In the precipitation of blood solution, we might at first expect that for producing the first observable quantity of precipitate the same quantity of precipitating salt would be sufficient at all concentrations-I per cent. as well as 0.17 per cent.-of the solution. If a mass action takes place, as is very probable, the higher concentration would even give the same quantity of precipitate with a smaller quantity of precipitating salt than the lower concentration. We observe just the contrary. 
This is explained in the following manner: If we add to the precipitate fresh blood solution, this dissolves the precipitate partially, and with a sufficient quantity, totally. This indicates that before the nearly insoluble precipitate is formed there exists in the solution another saltlike product containing less metal ions than the precipitate. If now this first product be a very strong combination, we will have to add quantities of salt proportional to the concentration of the blood solution (always used in the quantity of 5 (c) before the nearly insoluble precipitate is formed.

In other words, the necessary quantity of agglutinating salt will be porportional to the concentration. Now the quantity of salt increases more slowly than the concentration, which indicates that there exists a chemical equilibrium between the two salt-like products, deriver from the blood solution and the ions of the precipitating salt. This behavior cannot be easily explained from the point of view of the colloidal school, just as with the analogrous behavior of the agglutinating quantities.

All the facts in this investigation give strong arguments in favor of the physical-chemical theory, according to which the observed phenomena are due to chemical processes similar to those encountered in general chemistry, and in which the chemical equilibria play an important rôle.

Noler, Physico-chmical Institete. stockhoim, June 12, 190.4.

\section{ON THE NATURE OF PRECIPITATED COLLOIDS.}

BY II. W. FOOTE.

Received July : 1908 .

In this article experimental evidence is given tending to show that precipitated ferric and aluminium hyclroxides nay be regarded as solutions of water in ferric or aluminium oxides or in one of their lower hydroxides or more generally that they are solutions of a liquid in a solid.

Much experimental work has already been done on substances of this class. Van Bemmelen in particular has shown by a large amount of very careful work that colloidal precipitates like ferric hydroxide, aluminium hydroxide and silicic acid are not compounds of definite composition. He calls them absorption compounds. He has recognized clearly that the moist precipitates contain both water mechanically mixed with the precipitate and absorbed water, though he gives no means of distinguishing between the two. ${ }^{1}$ He considers that the amount of absorbed water is dependent on the structure of the jelly and that this amount is changed by the method of formation, by time, heating, and by the presence of foreign stibstances. He makes the statement that hydrogels

'7. amorg. (hom., 13, 2+t; 8 , 2t 